MATHEMATICS

\section{A life computed}

\section{James Poskett navigates a sophisticated account of Alan Turing's extraordinarily varied intellectual world.}

A lan Turing did not invent the computer. During the 1930s, well before the Manchester 'Baby', Pilot ACE or EDVAC machines, thousands were in operation all across Britain. These 'computers' were women, working in teams and each performing a discrete step of a complex mathematical operation.

Employed by the Scientific Computing Service (SCS) in the United Kingdom, these doughty women solved problems in everything from X-ray crystallography to jet-engine design. That world of 'computers before computers' is featured in the opening gallery of Codebreaker, the celebration of mathematician Alan Turing's life and legacy at London's Science Museum.

Although the SCS may seem far removed from Turing's world, knowledge of its work can help us to make sense of his seminal 1936 article 'On computable numbers, with an application to the Entscheidungsproblem'. This is viewed by some as the origin of the concepts behind the modern computer. But the real story is more complex.

Turing didn't pluck the idea of the modern computer out of thin air. He took the idea of a team of human computers working together

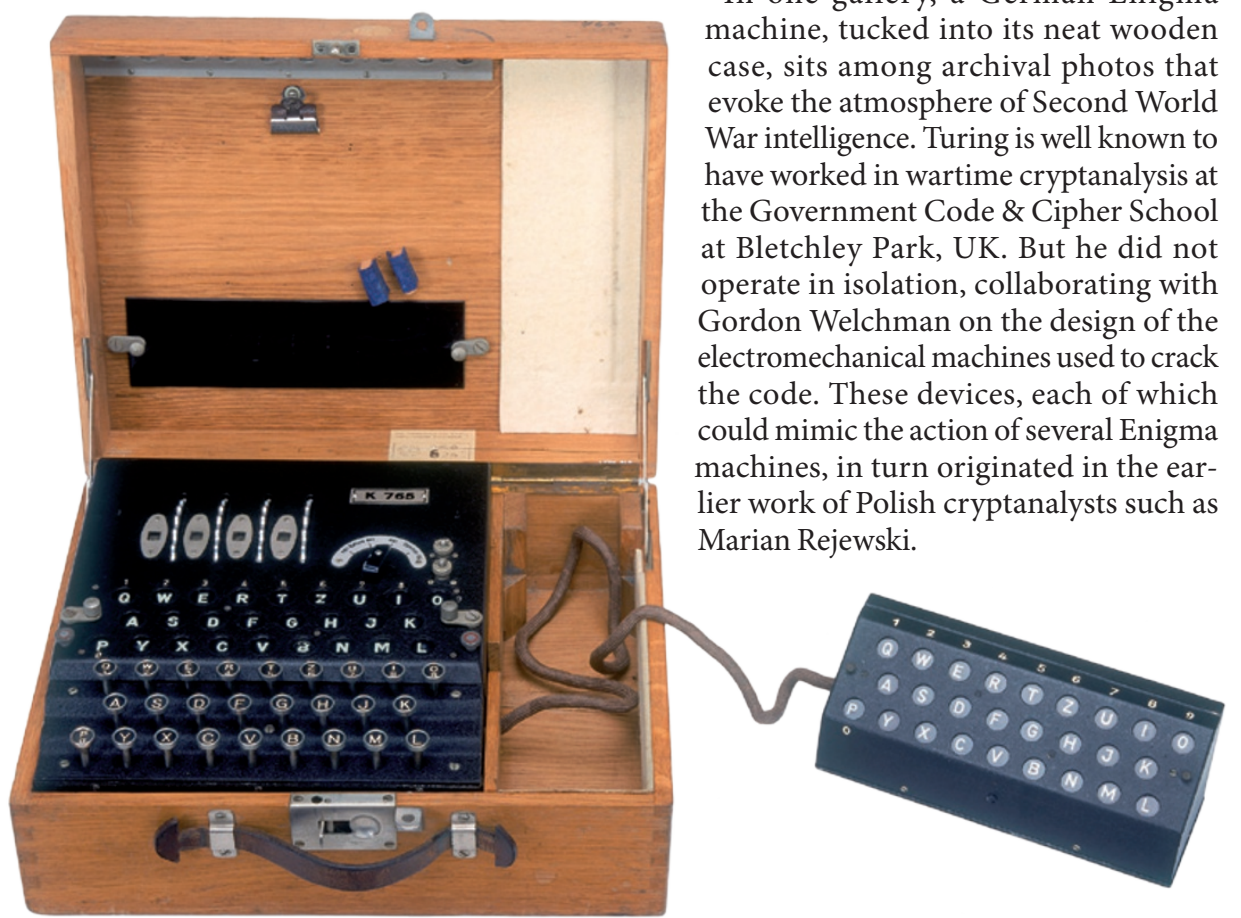

Alan Turing worked on devices to crack the German Enigma machine's code during the Second World War.
In a nearby gallery, a twisted white metal fuselage serves as a poignant reminder of the part Turing's ideas played in developing safer air travel after the war. In 1954, the world's first commercial jet airliner, the de Havilland Comet registered 'Yoke Peter', exploded in mid-air, killing everyone on board - and prompted the Royal Aircraft Establishment at Farnborough, UK, to find the cause.

By this time, Turing's abstract idea of a universal computing machine had become a reality. The National Physical Laboratory in Teddington, UK, had in 1950 completed the Pilot ACE, an electronic computer designed to one of Turing's first practical specifications. For a short time, this computer was the fastest in the world. The huge rack of wires, relays and coloured transistors is displayed alongside the Yoke Peter wreckage. It helped to process the enormous amounts of data needed to complete detailed analysis of the debris, eventually revealing the point of structural weakness and prompting improvements in the design and manufacture of de Havilland jets.

The exhibition also explores links between the Pilot ACE and Dorothy Hodgkin's work on the structure of vitamin $B_{12}$. One of her original models of the vitamin, an intricate web of more than 100 red and blue balls, is on show next to the story of her use of computers. Cryptography and X-ray crystallography had much in common at this time: each involved recovering information from a scrambled signal.

Hodgkin's problem was that the images she produced indicated only the amplitudes of the diffracted waves. To establish the correct structure of a molecule, she needed to churn through an enormous number of possible permutations of different wave phases. So she enlisted the help of both the SCS and the Pilot ACE, going on to win the Nobel Prize in Chemistry for her work in 1964.

Turing's relationships with artificial intelligence and developmental biology are also on show through video interviews with contemporary mathematical biologists that run next to programmable robotic tortoises. Although Turing didn't work on these machines himself, he was fascinated by the possibility of an artificial mind, coming to London especially to see robots such as these scurry across the floor at the Festival of Britain in 1951.

Codebreaker does an impressive job of bringing these diverse histories together. Turing is rightly celebrated, not as a lone genius, but as an impressive intellect and brilliant collaborator.

James Poskett is a science writer based in Cambridge, UK, specializing in the history and philosophy of science. e-mail:james.poskett@cantab.net 